\title{
Statistical analysis of geo-electric imaging and geotechnical test results - a case study
}

\author{
Rambhatla G Sastry ${ }^{1} *$, Sumedha Chahar ${ }^{1}$ and Manohar N ViladkaR ${ }^{2}$ \\ ${ }^{1}$ Department of Earth Sciences, Indian Institute of Technology Roorkee, Roorkee, India. \\ ${ }^{2}$ Department of Civil Engineering, Indian Institute of Technology Roorkee, Roorkee, India. \\ *Corresponding author.e-mail: rgss1fes@iitr.ac.in; rgssastry@gmail.com
}

MS received 18 October 2016; revised 22 September 2017; accepted 8 December 2017;

published online 25 June 2018

For conjunctive use of geoelectric imaging and geotechnical site investigations in geotechnical characterization of major civil engineering construction sites, an objective assessment of influencing factors is important. Here, we present multiple regression analyses of both geoelectric (Electrical Resistivity Tomography, ERT; Induced Polarization Imaging, IPI) and geotechnical site investigations (Standard Penetration Test, SPT) for two profiles at a construction site for CGEWHO Complex in Greater Noida region, Delhi to assess the role of influencing formation factors like sand, fines and water content. Achieved results show that SPT ' $\mathrm{N}$ ' and IPI are well predicted by a linear multiple regression. On an average, the nonlinear regression has improved predicted SPT ' $\mathrm{N}$ ', resistivity and chargeability by $28.55 \%, 22.45 \%$ and $9.58 \%$, respectively. The influence of sand and fines content is more than that of water content in the prediction of chargeability and SPT ' $\mathrm{N}$ '. RMS error is less in prediction of IPI chargeability (average error of $1.96 \%$ ) in comparison to SPT ' $N$ ' value (average error of $11.35 \%$ ). As factors affecting chargeability (IPI) and SPT ' $\mathrm{N}$ ' are similar, non-invasive IPI can be used along with few geotechnical site investigations for detailed geotechnical site investigations.

Keywords. SPT; ERT/IPI; multiple regression analysis; geoelectric imaging; geotechnical tests; linear and nonlinear multiple regression analysis.

\section{Introduction}

Geotechnical tests (Standard Penetration Test, SPT; Cone Penetration Test, CPT; Static Cone Penetration Test, SCPT; Dynamic Cone Penetration Test, DCPT and others) are performed to assess the mechanical properties of shallow soils either offshore or onshore before undertaking major civil engineering constructions. However, these point observations are both time-consuming and expensive. So, they are curtailed to a limited number, which itself is subjective and this decision very much depends on the experience and technical expertise of a geotechnical engineer. On the other hand cost-effective geoelectric imaging methods provide $2-\mathrm{D} / 3-\mathrm{D}$ resistivity and chargeability sections of subsurface on detailed scales and their recent conjunctive use in geotechnical site characterization has received wide attention (Sastry et al. 2012).

Index properties of soils (e.g., shape and size of grains, grain size distribution, water content, lithology, density index, and consistency), shear strength governed by Coulomb equation, formation and structure of soils and soil-phase relationships rule the results of geotechnical tests (Craig 


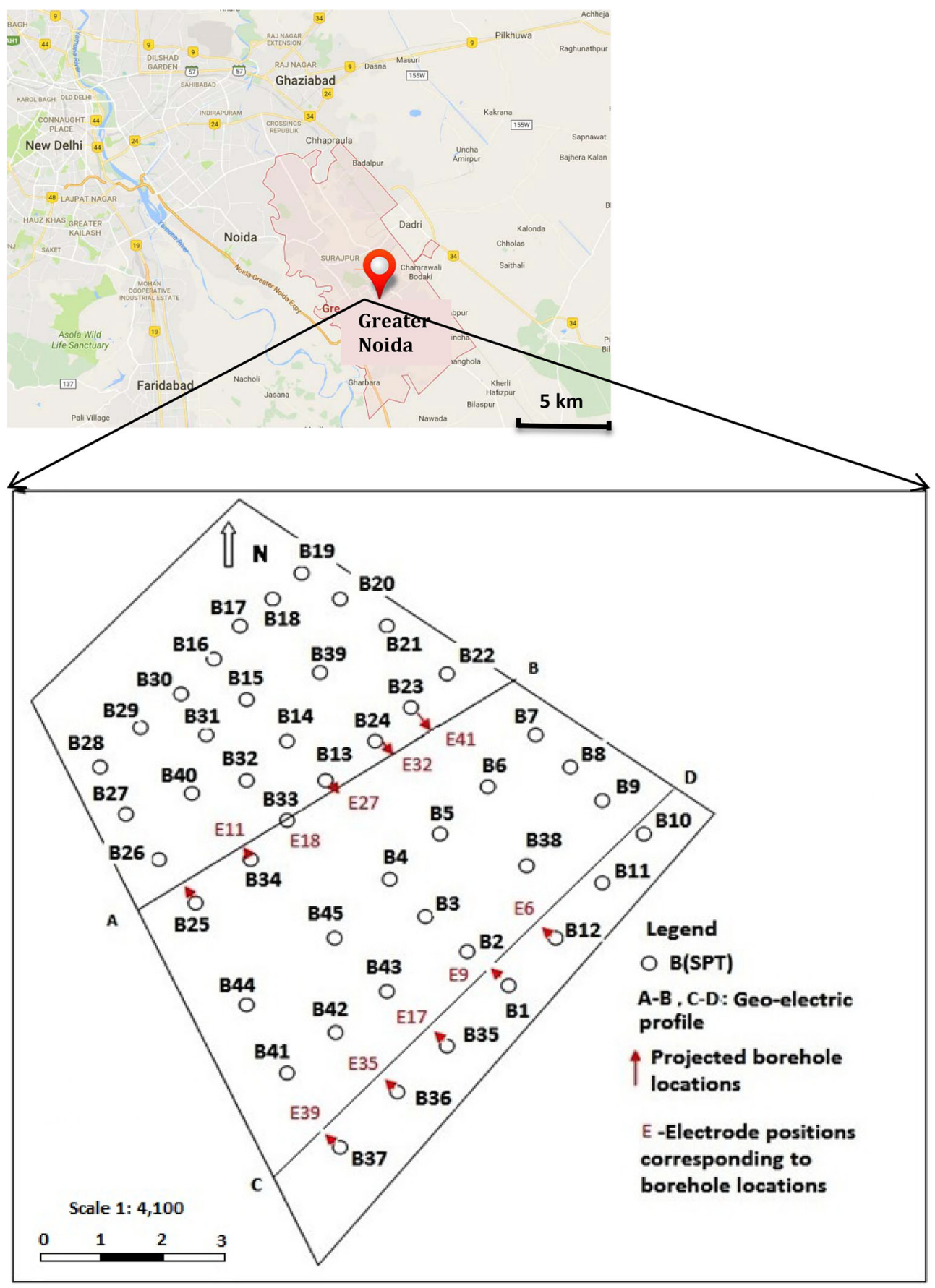

Figure 1. Site location map of proposed construction site of CGEWHO Complex in Greater Noida, India.

1978; Terzaghi 1943; Terzaghi and Peck 1996). SPT is affected by sand, grain size, clay, water content and porosity (Murthy 2008). SPT ' $N$ ' is directly proportional to grain size and clay content and inversely proportional to porosity and water content (Murthy 2008; Bowles 2001). CRP has been used by Yoon et al. (2009) for assessing the local behaviour in soft offshore soil. Apart from undrained shear strength there are other soil parameters (plasticity index, pore pressure coefficient, and over-consolidation ratio) that have an impact on SCPT measurements (Remai 2013). The quality of groundwater influences resistivity while it has no role on SPT 'N'. Pidlisecky et al. (2006) have developed 3-D distribution of electrical conductivity by the cone-based electrical resistivity tomography.

Detailed studies on electrical conductivity property of sedimentary rocks are undertaken by several workers (Li and Oldenburg 1991; Revil and Glover 1997, 1998; Revil et al. 1998; Revil and Leroy 2004). Laboratory studies have revealed that 


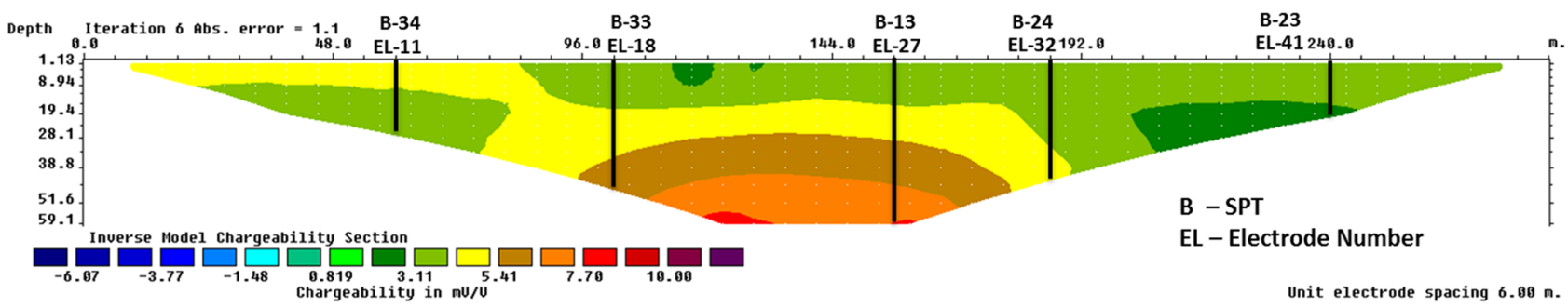

(a)

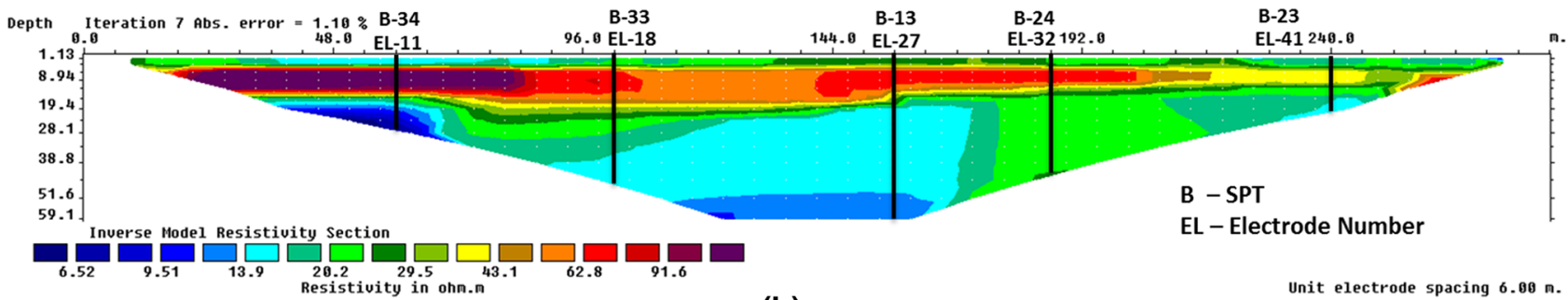

(b)

Figure 2. (a) True chargeability section for profile A-B (ref. figure 1). (b) True resistivity section for profile A-B (ref. figure 1).

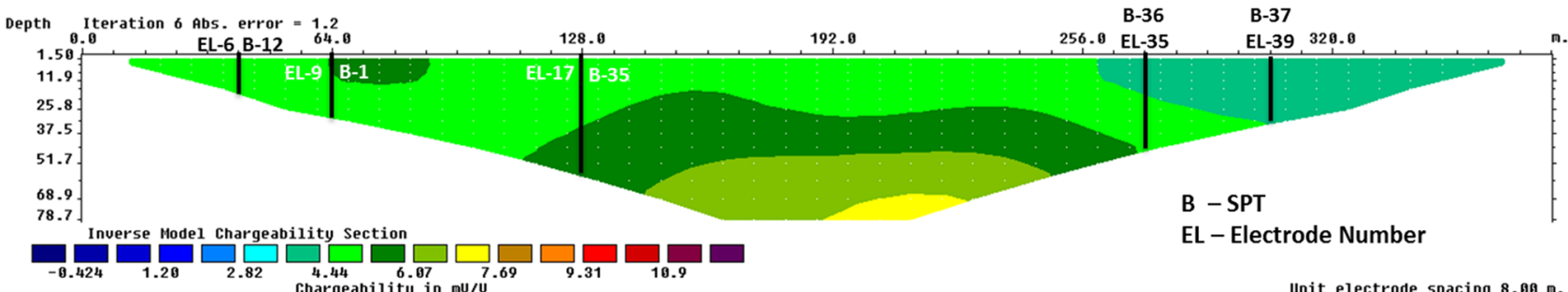

(a)

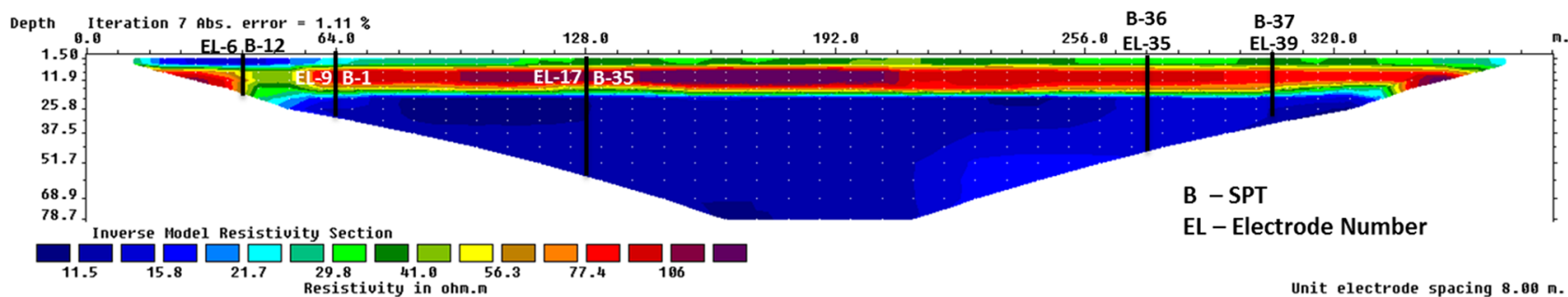

(b)

Figure 3. (a) True chargeability section for profile C-D (ref. figure 1). (b) True resistivity section for profile C-D (ref. figure 1).

the sensitivity of measured geophysical properties to solid-fluid, fluid-fluid and solid-solid interfaces in granular and fractured materials (Knight et al. 2010). Shevnin et al. (2007) have estimated clay content in soil through resistivity measurements both in field and laboratory. Clay content, fluid conductivity and microstructure affect electrical properties in a complex fashion (Slater and Glaser 2003). Resistivity of earth materials is inversely proportional to porosity, clay content and water content, while it is directly proportional to grain size of rock matrix and air content in vadose zone. Niwas et al. (2006, 2007) have proposed a computational scheme for simplifying the nonlinear electrical response of shaly sand reservoir. IP method can be used to characterize clay and shaly sands (Sumner 1976; Marshall and Madden 1959; Patella 1973) in the subsurface. The IP logging can be operated in the frequency and time domains to estimate the hydraulic properties of shaly sands (Vinegar and Waxman 1984; Worthington and Collar 1984; Börner et al. 1996; 
Table 1. Subsoil borelog at borehole location B13.

\begin{tabular}{|c|c|c|c|c|c|c|c|c|}
\hline \multirow{2}{*}{$\begin{array}{l}\text { Depth } \\
(\mathrm{m})\end{array}$} & \multirow{2}{*}{$\begin{array}{c}\text { Water } \\
\text { table }(\mathrm{m})\end{array}$} & \multirow{2}{*}{$\begin{array}{c}\text { I.S. } \\
\text { classification }\end{array}$} & \multicolumn{3}{|c|}{ Grain size analysis } & \multirow{2}{*}{$\begin{array}{l}\text { Liquid } \\
\text { limit (\%) }\end{array}$} & \multirow{2}{*}{$\begin{array}{c}\text { Plastic } \\
\text { limit (\%) }\end{array}$} & \multirow{2}{*}{$\begin{array}{c}\text { Natural water } \\
\text { content }(\%)\end{array}$} \\
\hline & & & Gravels (\%) & Sand $(\%)$ & Fines $(\%)$ & & & \\
\hline 1.5 & & $\mathrm{CL}$ & 0.0 & 4.8 & 95.2 & 32.3 & 19.9 & 18.1 \\
\hline 3.0 & & ML (NP) & 0.0 & 30.2 & 69.8 & NP & $\mathrm{NP}$ & 17.4 \\
\hline 4.5 & & $\mathrm{SM}(\mathrm{NP})$ & 4.0 & 78.0 & 18.0 & $\mathrm{NP}$ & NP & 27.4 \\
\hline 6.0 & $6.50 \nabla$ & SP-SM & 1.0 & 89.0 & 10.0 & NP & NP & 27.8 \\
\hline 7.5 & & SP-SM & 7.3 & 84.4 & 8.3 & NP & NP & 26.2 \\
\hline 9.0 & & SP-SM & 0.5 & 92.2 & 7.3 & NP & NP & 26.2 \\
\hline 10.5 & & SP-SM & 1.0 & 90.2 & 8.8 & NP & NP & 26.3 \\
\hline 12.0 & & $\mathrm{SM}(\mathrm{NP})$ & 1.0 & 84.0 & 15.0 & NP & NP & 25.6 \\
\hline 13.5 & & SP-SM & 1.3 & 93.0 & 5.7 & NP & NP & 26.0 \\
\hline 15.0 & & $\mathrm{SP}$ & 0.0 & 95.7 & 4.3 & NP & NP & 26.1 \\
\hline 18.0 & & SP-SM & 0.0 & 92.5 & 7.5 & NP & NP & 23.1 \\
\hline 21.0 & & CI & 2.5 & 15.0 & 82.5 & 39.0 & 20.5 & 23.5 \\
\hline 24.0 & & CI & 3.3 & 7.7 & 89.0 & 38.4 & 22.7 & 21.5 \\
\hline 27.0 & & CI & 0.0 & 14.5 & 85.5 & 39.0 & 22.3 & 21.2 \\
\hline 30.0 & & $\mathrm{SM}(\mathrm{NP})$ & 0.0 & 87.5 & 12.5 & NP & $\mathrm{NP}$ & 26.5 \\
\hline
\end{tabular}

Lesmes and Morgan 2001; Slater and Lesmes 2002; Titov et al. 2002, 2004). The role of water content and cation exchange capacity (CEC) of clay minerals/shale was investigated by Kiberu (2002).

Sastry et al. (2013) used geoelectric imaging for geotechnical site characterization when conventional geotechnical field tests failed. Gautam et al. (2007) have explored the possibility of predicting site geotechnical test results (SPT, DCPT and SCPT) through a conjunctive use of geoelectrical (ERT and IPI) and few geotechnical data. Even though their prediction is based on regression analysis, they have not carried out any quantitative multiple regression analysis to fix the key parameters affecting both types of measurements.

Till date, to our knowledge, proper in-depth analysis and performance of geo-mechanics related geotechnical tests (SPT, DCPT, SCPT and other similar tests) and geoelectrical characteristics (resistivity, chargeability) governing geoelectric imaging results (ERT and IPI) of near-surface soil have not been thoroughly explored. Sumedha and Sastry (2016) have reported initial multiple regression results concerning geoelectric and geotechnical site investigation results.

So, the present study is devoted to a combined multivariate analysis of both data sets (ERT/IP and SPT) acquired at a study region (construction site for CGEWHO Complex) in Greater Noida, Uttar Pradesh, India with a prime objective of identifying the key factors controlling mechanical and electrical properties of near surface soils. In this article, section 2 is devoted to methodology and multi-regression analysis, section 3 to discussion and section 4 to conclusions.

\section{Methodology}

In an experiment, for establishing either a linear or non-linear relationship between independent and dependent variables, one opts for a multiple regression analysis (MRA), which provides additional statistical information about the regression results.

In our case, the chosen independent factors affecting both geotechnical (SPT ' $\mathrm{N}$ ') and geoelectrical (resistivity and chargeability) parameters are sand $\left(\mathrm{x}_{1}\right)$, fines $\left(\mathrm{x}_{2}\right)$ and water content $\left(\mathrm{x}_{3}\right)$ of near-surface soil. Thus, field test results like SPT 'N', inverted ERT (true resistivity) and IPI (chargeability) logs/sections constitute the dependent parameters.

\subsection{Site and geological description}

Our study region (figure 1) belongs to PleistoceneHolocene period (Gupta and Subramanian 1994) and it is located at CGEWHO Complex, Greater Noida (Okhla Industrial Development Authority, NOIDA), a satellite town $\left(28.57^{\circ} \mathrm{N}, 77.32^{\circ} \mathrm{E}\right)$ of Delhi. It is bound on the west and south-west by the Yamuna River and by the Hindon River on the north, east and south-east (Kikon and Singh 2014). The soils at the site belong to the 'Indo-Gangetic Alluvium' and are river deposits of the Yamuna and its tributaries (Parkash et al. 
Table 2. Subsoil borelog at borehole location B35.

\begin{tabular}{|c|c|c|c|c|c|c|c|c|}
\hline \multirow{2}{*}{$\begin{array}{l}\text { Depth } \\
(\mathrm{m})\end{array}$} & \multirow{2}{*}{$\begin{array}{c}\text { Water } \\
\text { table }(\mathrm{m})\end{array}$} & \multirow{2}{*}{$\begin{array}{c}\text { I.S. } \\
\text { classification }\end{array}$} & \multicolumn{3}{|c|}{ Grain size analysis } & \multirow{2}{*}{$\begin{array}{l}\text { Liquid } \\
\text { limit (\%) }\end{array}$} & \multirow{2}{*}{$\begin{array}{c}\text { Plastic } \\
\text { limit (\%) }\end{array}$} & \multirow{2}{*}{$\begin{array}{c}\text { Natural water } \\
\text { content }(\%)\end{array}$} \\
\hline & & & Gravels (\%) & Sand $(\%)$ & Fines $(\%)$ & & & \\
\hline 1.5 & & CL & 0.0 & 13.7 & 86.3 & 32.9 & 19.5 & 28.5 \\
\hline 3.0 & & $\mathrm{SM}(\mathrm{NP})$ & 0.0 & 86.7 & 13.3 & NP & $\mathrm{NP}$ & 14.4 \\
\hline 4.5 & & SP-SM & 0.0 & 89.2 & 10.8 & NP & NP & 27.1 \\
\hline 6.0 & $6.50 \boldsymbol{\nabla}$ & SP-SM & 0.0 & 92.0 & 8.0 & NP & NP & 26.6 \\
\hline 7.5 & & SP-SM & 0.0 & 94.2 & 5.8 & NP & NP & 24.4 \\
\hline 9.0 & & SP-SM & 0.0 & 93.7 & 6.3 & NP & NP & 26.3 \\
\hline 10.5 & & $\mathrm{SP}$ & 0.0 & 95.3 & 4.7 & NP & NP & 28.2 \\
\hline 12.0 & & $\mathrm{SP}$ & 0.0 & 95.5 & 4.5 & $\mathrm{NP}$ & NP & 25.9 \\
\hline 13.5 & & $\mathrm{SP}$ & 0.5 & 95.2 & 4.3 & NP & NP & 27.4 \\
\hline 15.0 & & SP & 5.3 & 90.0 & 4.7 & NP & NP & 46.9 \\
\hline 18.0 & & SP & 1.8 & 94.7 & 3.5 & NP & NP & 30.4 \\
\hline 21.0 & & SP-SM & 2.5 & 91.7 & 5.8 & NP & NP & 22.3 \\
\hline 24.0 & & SP/SP-SM & 0.5 & 94.5 & 5.0 & NP & $\mathrm{NP}$ & 22.9 \\
\hline 27.0 & & CL-ML & 0.0 & 27.0 & 73.0 & 25.9 & 19.1 & 25.4 \\
\hline 30.0 & & $\mathrm{SP} / \mathrm{SP}-\mathrm{SM}$ & 0.0 & 95.0 & 5.0 & NP & $\mathrm{NP}$ & 24.1 \\
\hline
\end{tabular}

2001). The Pleistocene and Recent deposits of the Indo-Gangetic Basin (Krishnan 1986) are composed of gravels, sands, silts and clays. The soils at the site classify primarily as sandy silt/clayey silt to about 2-3 m depth, underlain by fine sand to about $15 \mathrm{~m}$ depth (Gupta et al. 2010).

\subsection{Data acquisition, processing and interpretation}

Figure 1 depicts the position location of different geoelectrical field profiles and boreholes for SPT studies in the study region. The ERT and IPI data (figure 1) were acquired using SYSCAL Jr. 48 electrode system with a $6-\mathrm{m}$ electrode separation along a profile $(\mathrm{A}-\mathrm{B})$ and $8 \mathrm{~m}$ along profile $(\mathrm{C}-\mathrm{D})$ under Wenner-Schlumberger configuration (Pazdirek and Blaha 1996). Three-fold objectives that govern the choice of electrode separations are outlined in section 3. Data was processed using software PROSYS II and interpreted through software RES2D INV (Loke and Barker 1995). For illustration sake, we consider inverted ERT/IPI sections along Profiles $\mathrm{AB}$ and $\mathrm{CD}$ with projected nearby SPT boreholes (figure 1), leading to coincident depth-wise SPT 'N', true resistivity and chargeability logs for a multiple regression analysis in later sections.

Conventional geotechnical SPT borehole measurements followed by laboratory analysis of soil samples for index properties of soils and subsequent analysis were undertaken. The soil classification is predominantly grain size based. The grain size distribution is carried out by the mechanical sieve analysis for coarse-grained soils and hydrometer analysis for fine-grained soils (Ranjan and Rao 2000). Further classification is also done on the basis of the plasticity characteristics obtained via the Atterberg limits (for fine-grained soils like, clay and silt) method. A set of standard sieves is used to perform mechanical sieve analysis. Fine-grained soils having more than $50 \%$ material passing the No. 200 (0.075 $\mathrm{mm}$ sieve) are classified as silt (M) and clay (C), based on their liquid limit and plasticity index (Ranjan and Rao 2000). Soils can have dual symbols. These are used when the percentage of fine-grained fraction lies in the range of $5-12 \%$. Possible dual symbols are GM-ML, GM-MI, GM-MH, GC-CL, GC-CI, GC-CH, SM-ML, SM-MI, SM-MH, SC-CL, SC-CI, SC-CH as per Indian Standard (IS: 1498-1970). Water content is the ratio of the weight of water to the weight of soil solids (\%). The moisture content (\%) is obtained on basis of laboratory oven drying method. The geotechnical laboratory measurements of each borehole yield depth-wise distribution of sand (\%), fines content (\%) and water content $(\%)$.

For proper correlation of geoelectric data with geotechnical data (SPT ' $N$ '), we project numerous nearby boreholes on to geoelectric profile sections (ERT/IPI profiles) and consider respective SPT ' $N$ ', resistivity and chargeability logs for a multi-regression analysis. As units of input data (ERT/IPI, SPT and geotechnical laboratory data) are different, we normalize the individual data (ERT/IPI, SPT and geotechnical laboratory 


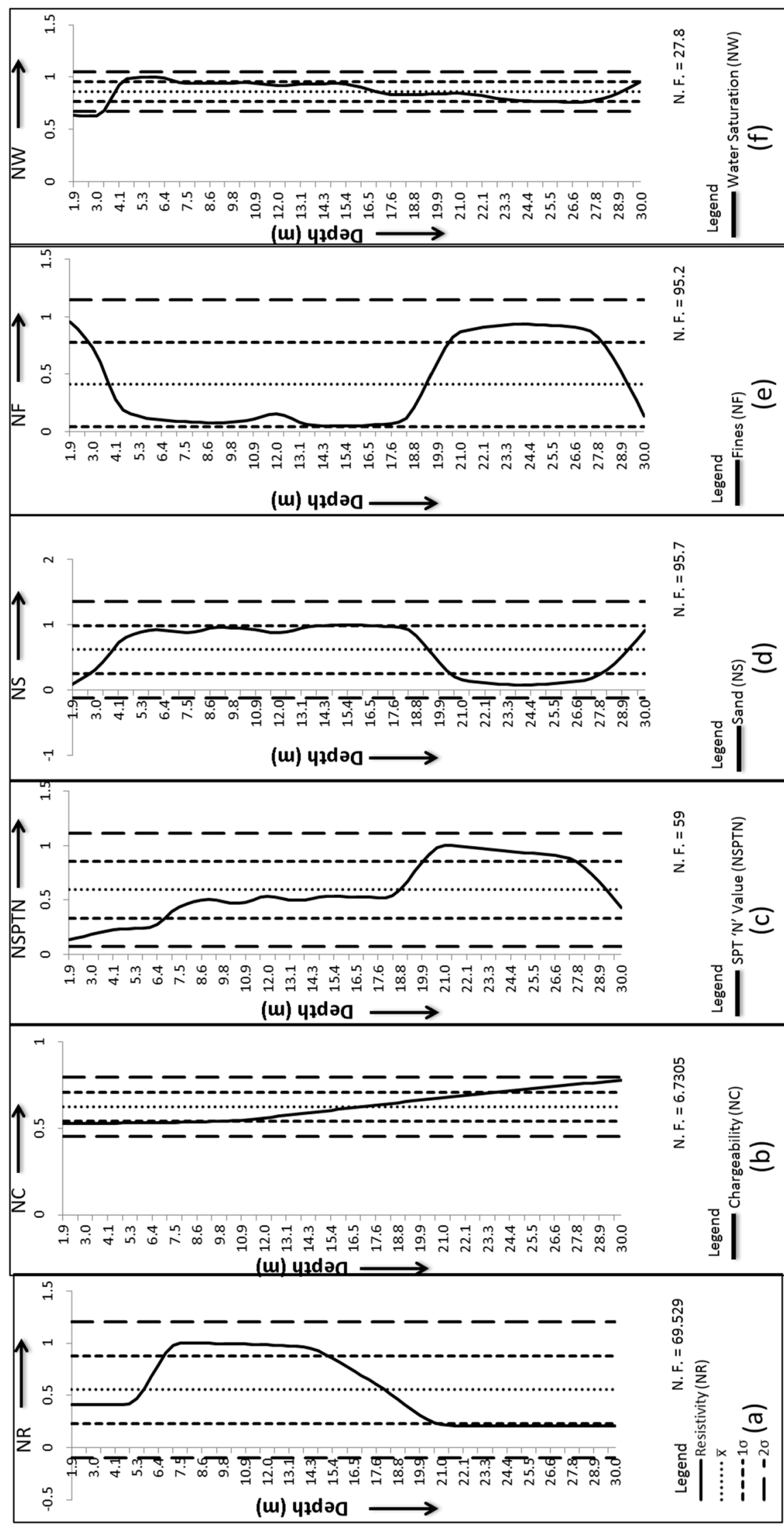




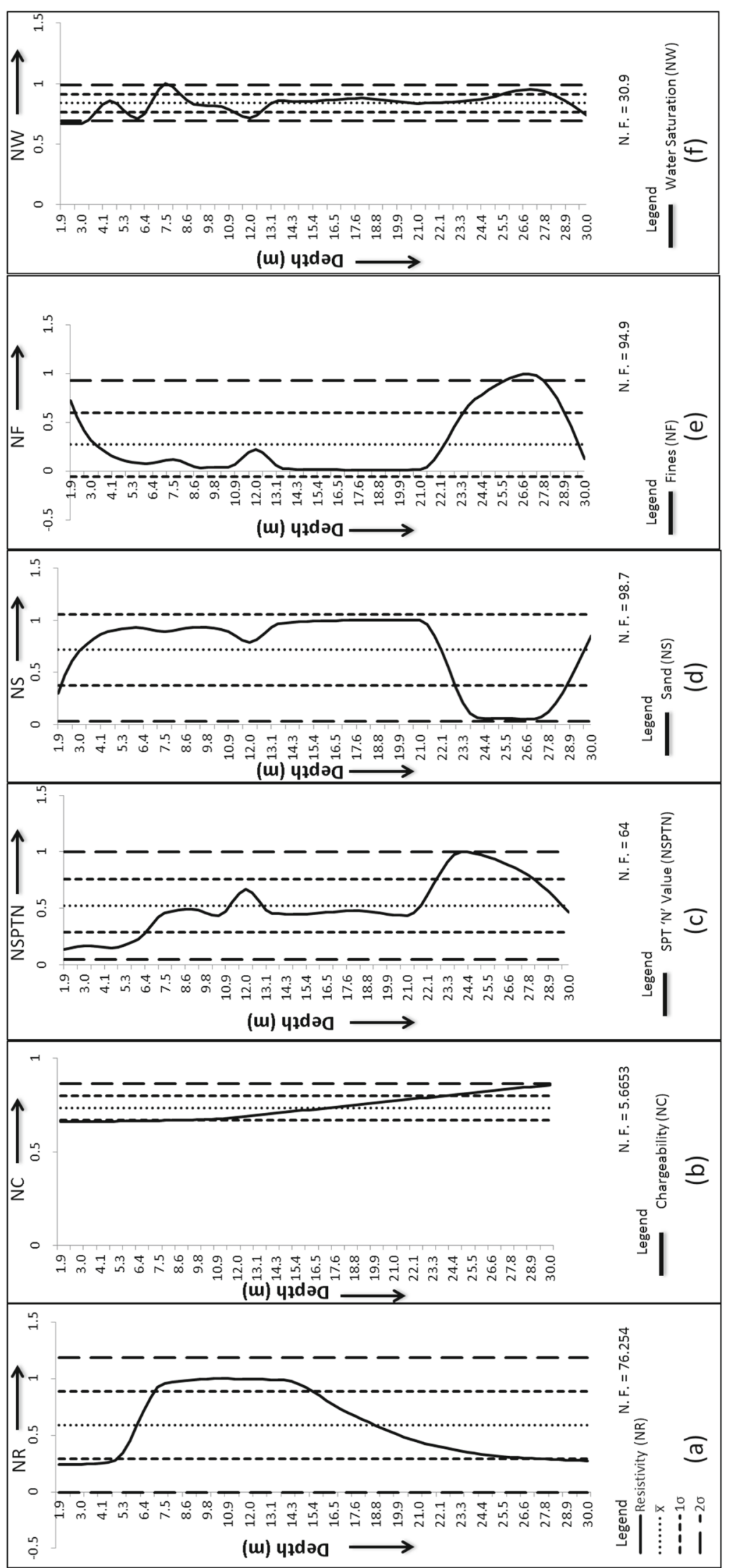

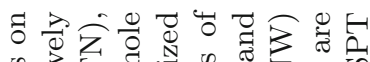

记

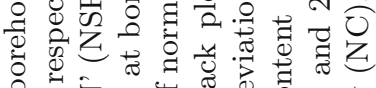

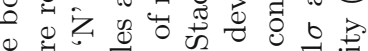

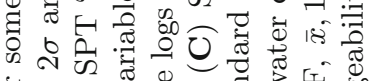

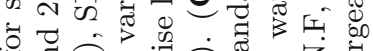

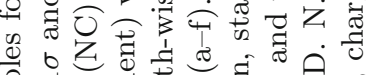

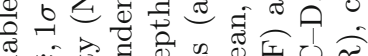

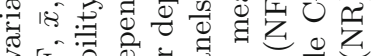

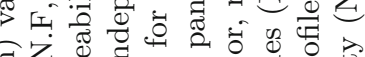

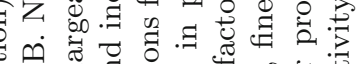
य

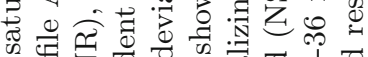
t)

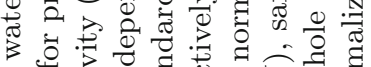

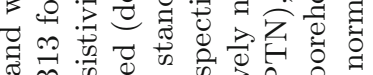

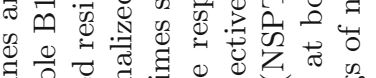

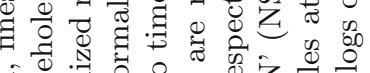

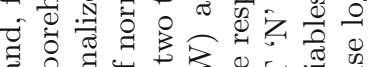

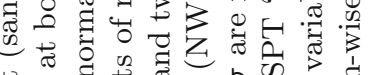

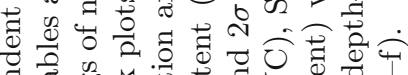

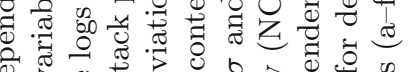

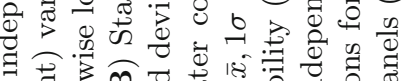

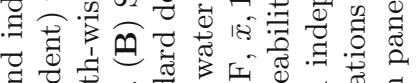

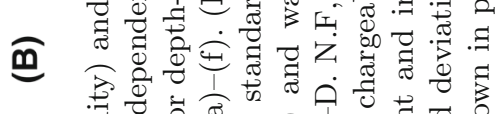

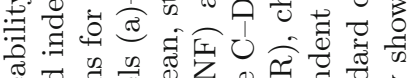

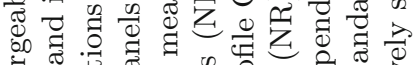

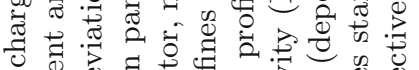

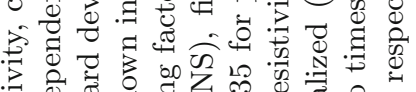

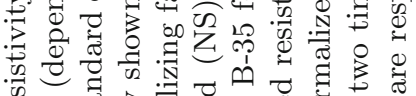

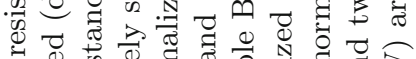

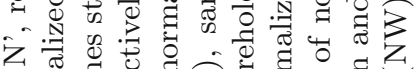

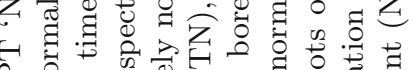

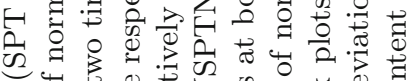

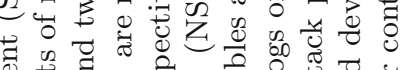

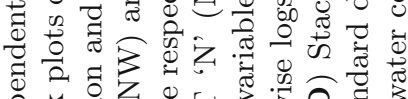

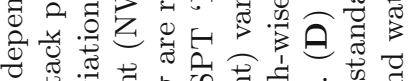

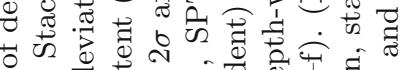

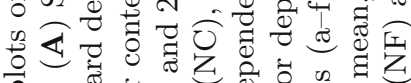
元要

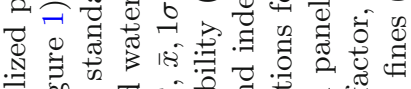
ฮี

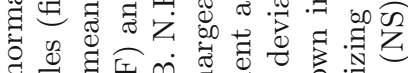

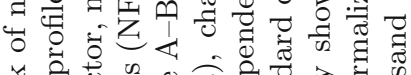
पे

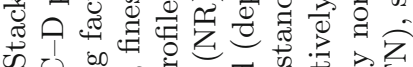

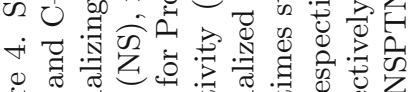

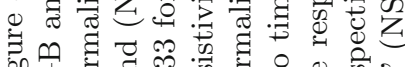

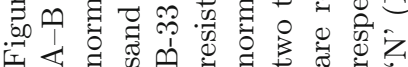




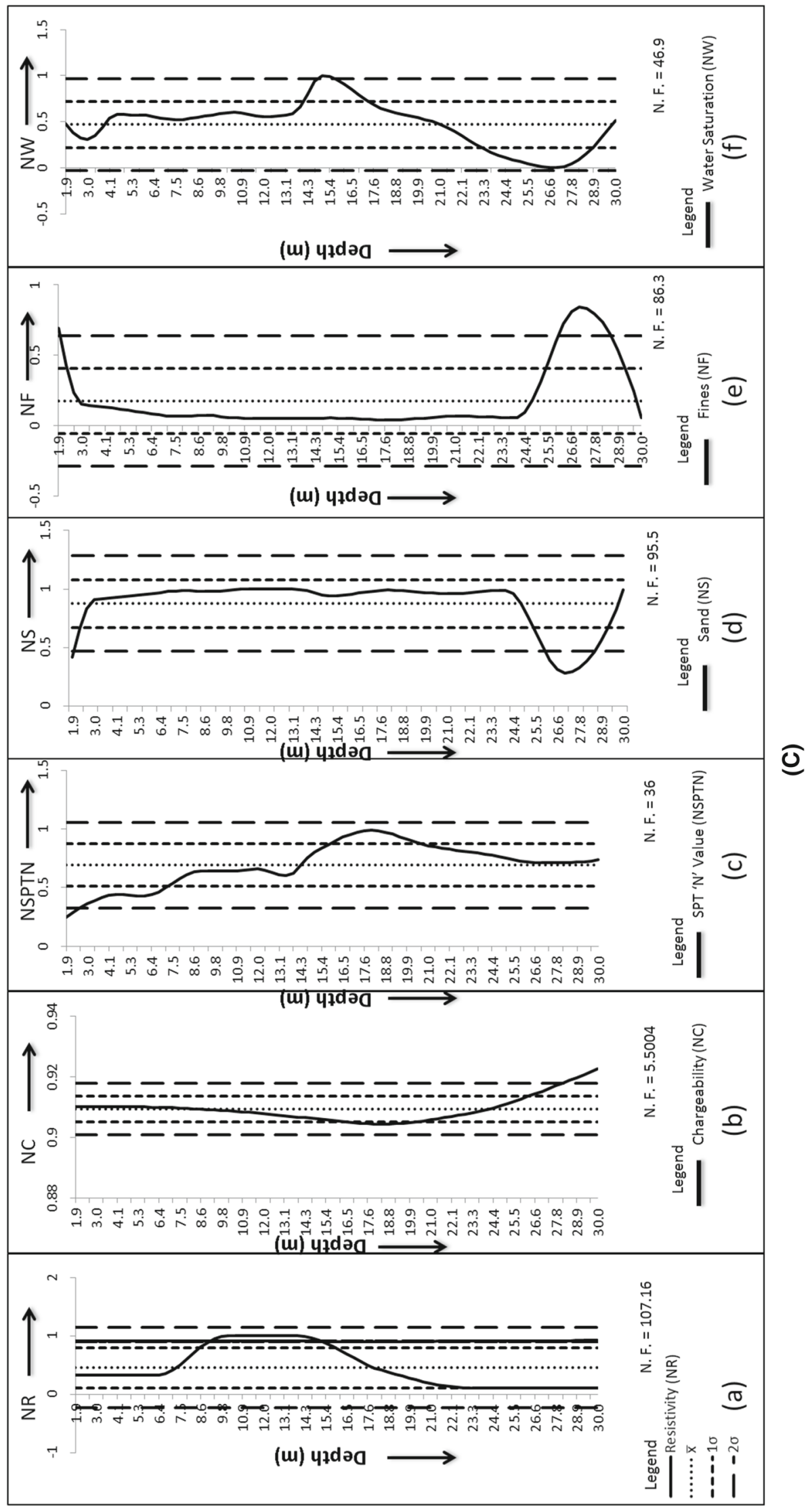




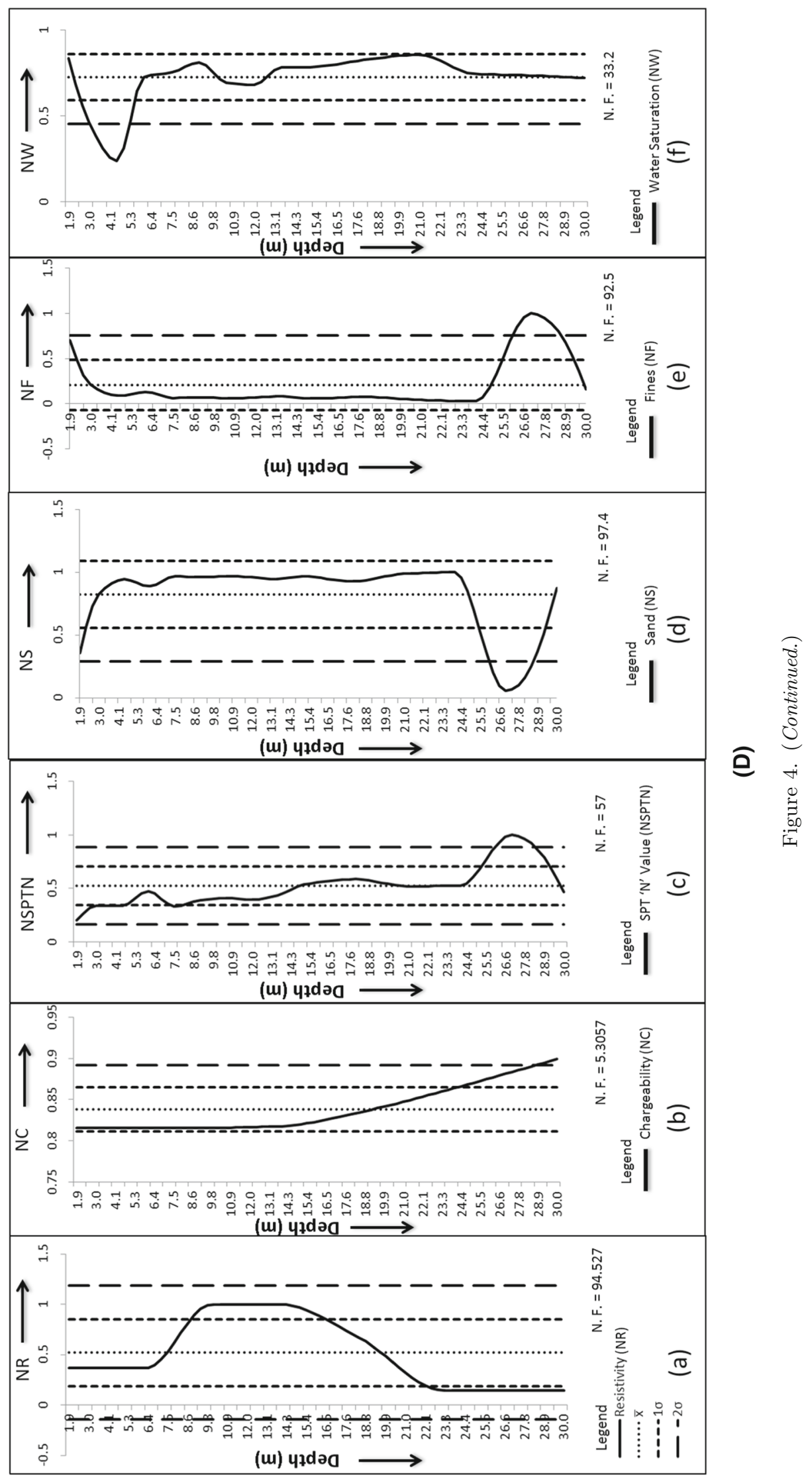


data) sets by their respective maximum values. In order to match the depth-wise sampling of true resistivity and chargeability logs to that of SPT ' $\mathrm{N}$ ', we adopted cubic splines for mathematical interpolation.

\subsection{Multiple-regression analysis results}

True resistivity and chargeability sections for two profiles, A-B and $\mathrm{C}-\mathrm{D}$ with projected geotechnical borehole (SPT) locations are shown in figures 2 and 3, respectively. Details of sub-soil borelogs at borehole location B13 and B35 are provided in tables 1 and 2, respectively.

Before undertaking a multiple regression analysis exercise, all data sets are normalized borehole-wise by respective maxima. MS excel based softwares, Analysis of variance (ANOVA) and Statistical package for social sciences (SPSS) have been used to carry out linear and nonlinear multiple regression analyses respectively.

Figure 4 shows the stacks of normalized plots of both dependent (SPT ' $N$ ', true resistivity and true chargeability) and independent variables (sand, fines and water content) of two boreholes each along profiles $\mathrm{A}-\mathrm{B}$ (figure $4 \mathrm{a}, \mathrm{b}$ ) and $\mathrm{C}-\mathrm{D}$ (figure $4 \mathrm{c}, \mathrm{d}$ ). These input stacks contain dimensionless variable logs along with vertical bands of their means $(\bar{x}), \pm 1 \sigma$ ( $\bar{x} \pm$ one standard deviation) and $\pm 2 \sigma$ ( $\bar{x} \pm$ two times standard deviation). The depth-wise variation of any of the dependent/independent variables can be qualitatively analyzed using figure 4 . The quantitative results are summarized in figures 5-8. In figures 5-8, we include multi-regression based prediction results concerning a pair of boreholes on each profile $(\mathrm{A}-\mathrm{B}$ and $\mathrm{C}-\mathrm{D})$.

\subsubsection{Regression analysis}

After performing MRA, one can get regression equation linking independent variables with that of dependent variable along with relevant statistical information in a standard format, often referred to as ANOVA (analysis of variance) table. Besides, comparative plots of original and reconstructed dependent variable versus depth are also provided so that one can judge the quality of a linear regression. If necessary, one can opt for a non-linear multiple regression analysis. The linear multiple regression analysis is dealt in three stages, viz., regression statistics, analysis of variance (ANOVA) including regression coefficients and prediction quality.

The adjusted $R^{2}$ is normally recommended in multiple regression analysis, if more than one independent variable, $x$ exists. Great interest is in $R^{2}$ term as it reveals the variation of dependent variable, $y_{i}$ around $\bar{Y}$ (its mean) is explained by $x_{1 i}$ through $x_{n i}$.

\subsubsection{Regression statistics}

After performing linear multiple regression analysis, one can get standard outputs as depicted in tables 3 and 4 (for profile $\mathrm{A}-\mathrm{B}$ ) with relevant regression equations. Both these tables refer to same borehole, B13 on Profile A-B. Similar tables for other boreholes on profiles $\mathrm{A}-\mathrm{B}$ and $\mathrm{C}-\mathrm{D}$ are not included here, but a gist of all the boreholes appear in tables 5-7.

\subsubsection{Analysis of variance (ANOVA)}

Here the analysis is carried out in respect of regression, residual and total. Under regression mode (Kleinbaum et al. 1988), depending upon the degrees of freedom ( $\mathrm{df}$, number of independent variables) the sum of squares (SS), mean square (MS) and F-statistic (F) are evaluated. A low Ftest significance (Kleinbaum et al. 1988) indicates that results accrued are not random.

\section{Discussion}

The geoelectric imaging sections clearly indicate that the heterogeneities exist in both lateral and vertical depth directions and nowhere have we assumed a homogeneity condition for our study.

The choice of 6 and $8 \mathrm{~m}$ for electrode spacings along geoelectric profiles, $\mathrm{A}-\mathrm{B}$ and $\mathrm{C}-\mathrm{D}$ is made on three considerations, viz., expected 1-D subsurface lithologies from geological view point as the site is away from foothills of Himalaya, to match the profile extents with the spread of boreholes in study area and to meet the deep resistivity and chargeability information matching with SPT logs. This choice conforms to our primary goal of multiregression analysis of resistivity, chargeability and SPT in terms of influencing parameters like sand $(\%)$, fines content (\%) and water content (\%) at different borehole positions.

The present study is a small beginning, which is limited to three independent variables that influence both geoelectric and geotechnical data sets. 


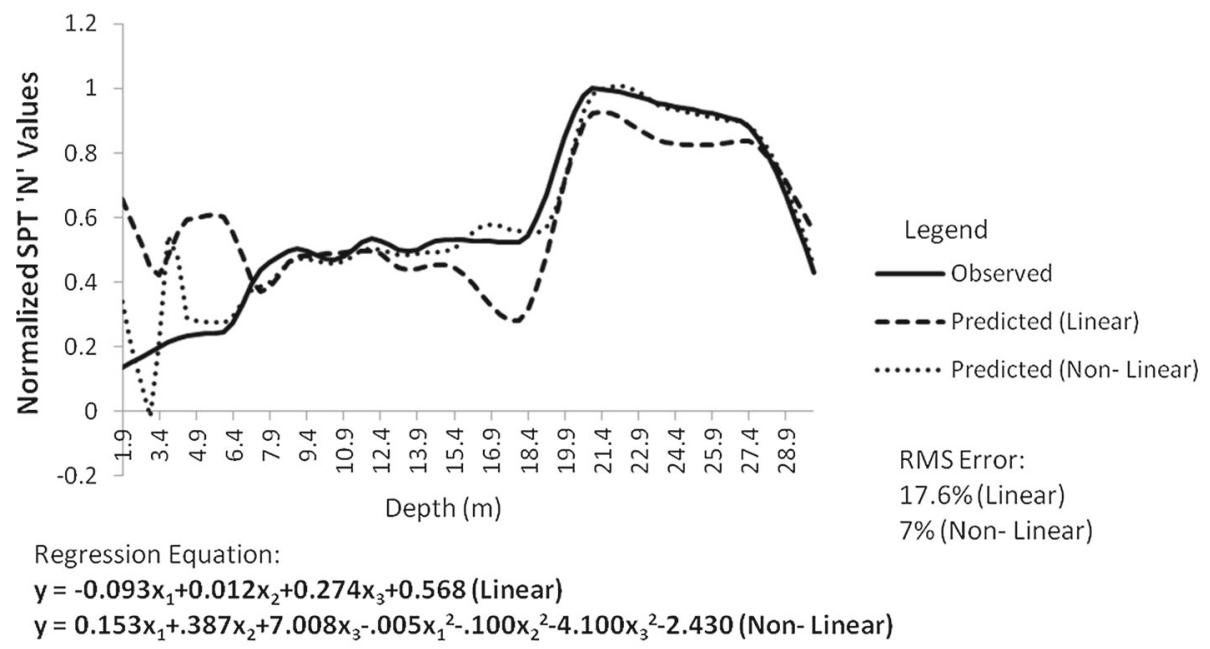

(a)

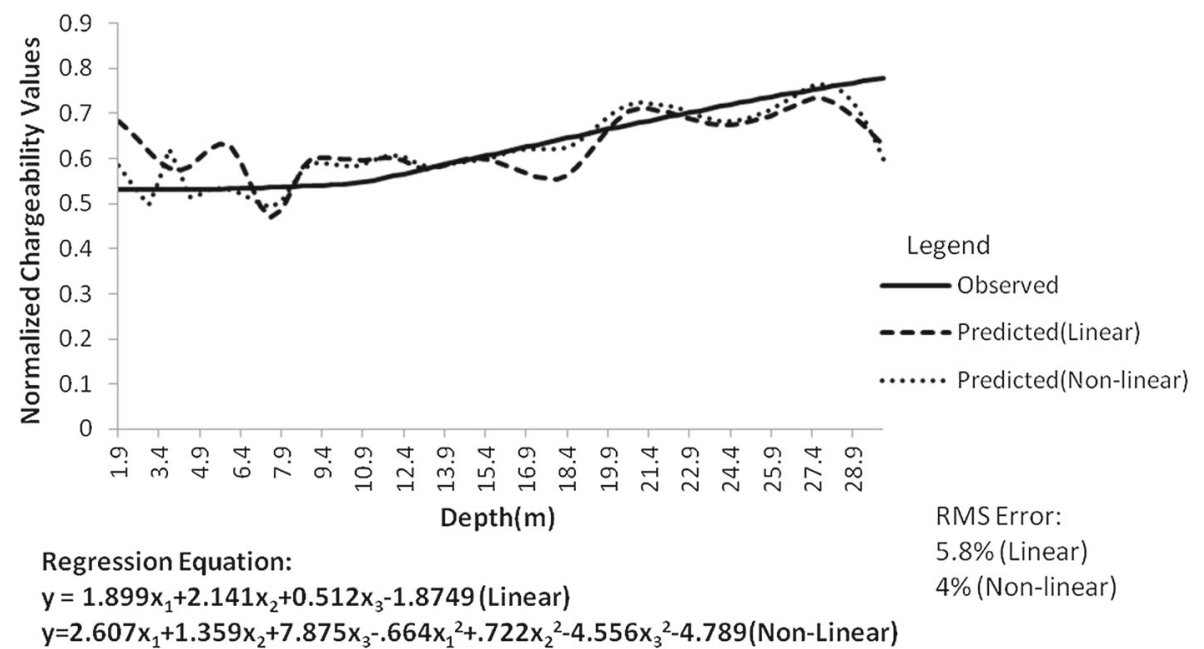

(b)

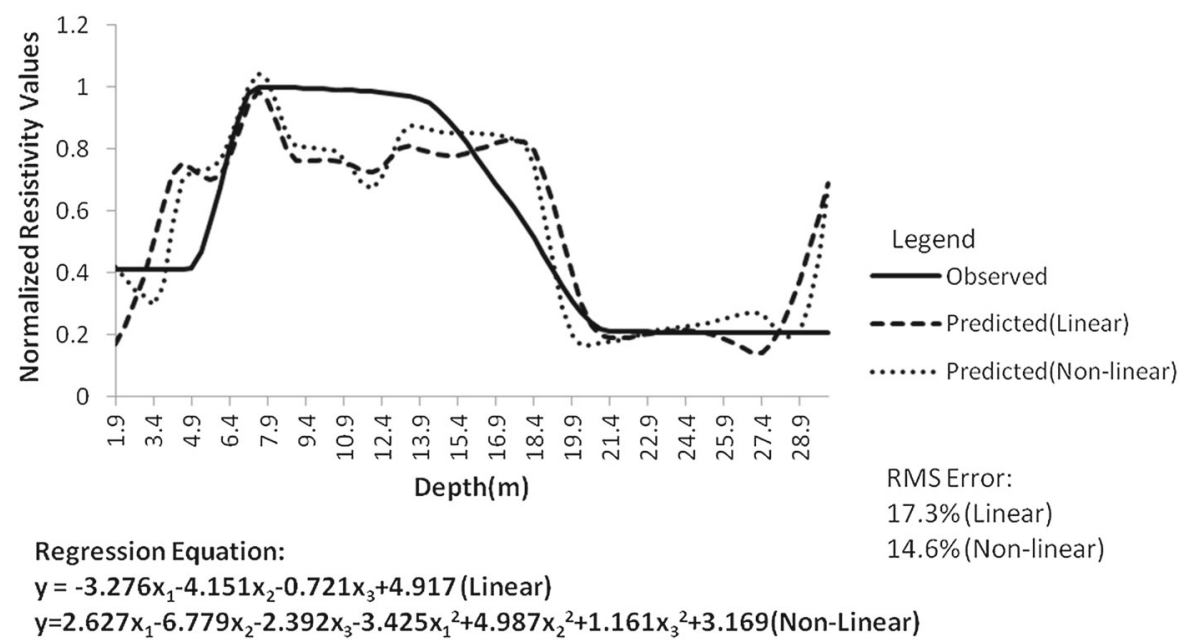

(c)

Figure 5. Observed and predicted (both linear and non-linear) SPT 'N', chargeability and resistivity curves at B13, profile A-B. (a) SPT 'N' curves. (b) Chargeability curves. (c) Resistivity curves. 


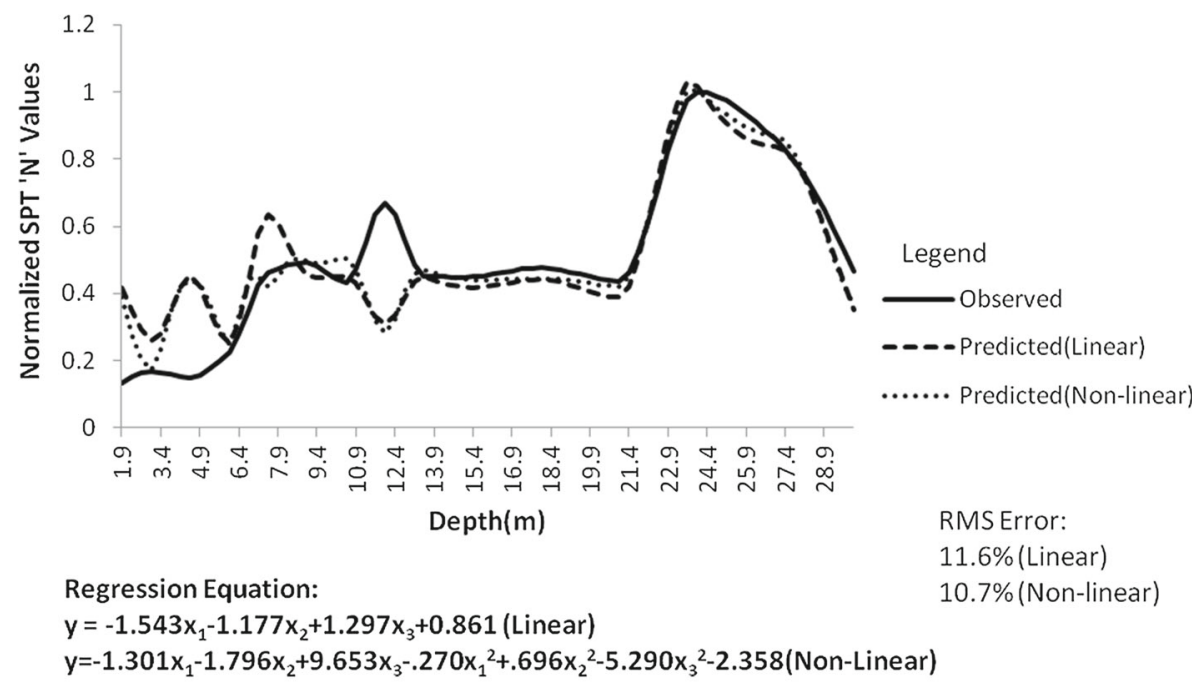

(a)

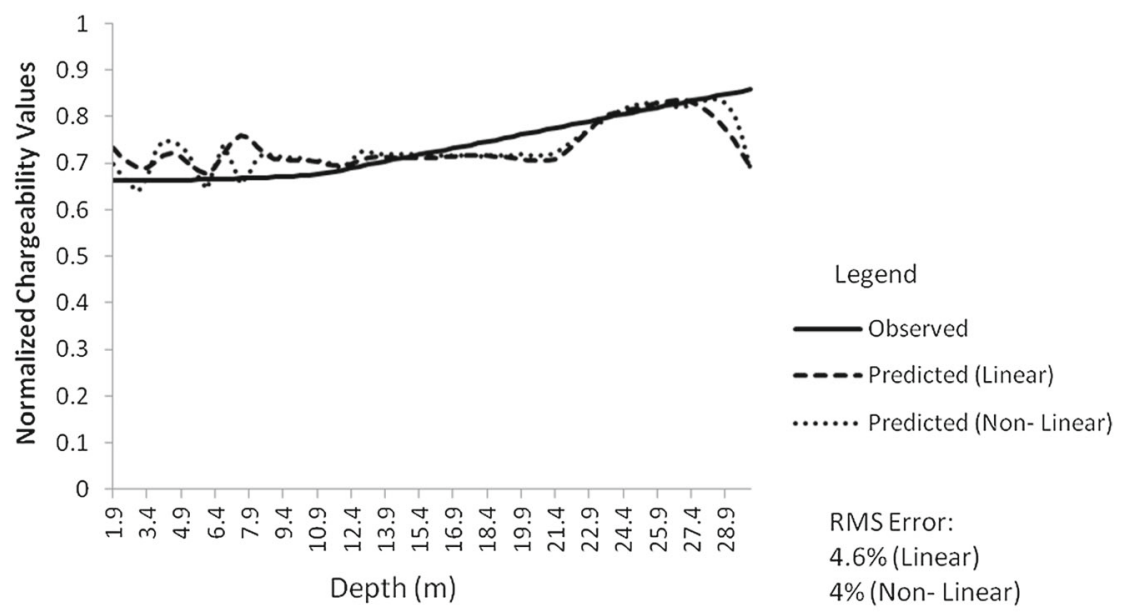

Regression Equation:

$y=-0.093 x_{1}+0.012 x_{2}+0.274 x_{3}+0.568$ (Linear)

$y=0.153 x_{1}+.387 x_{2}+7.008 x_{3}-.005 x_{1}^{2}-.100 x_{2}^{2}-4.100 x_{3}^{2}-2.430$ (Non- Linear)

(b)

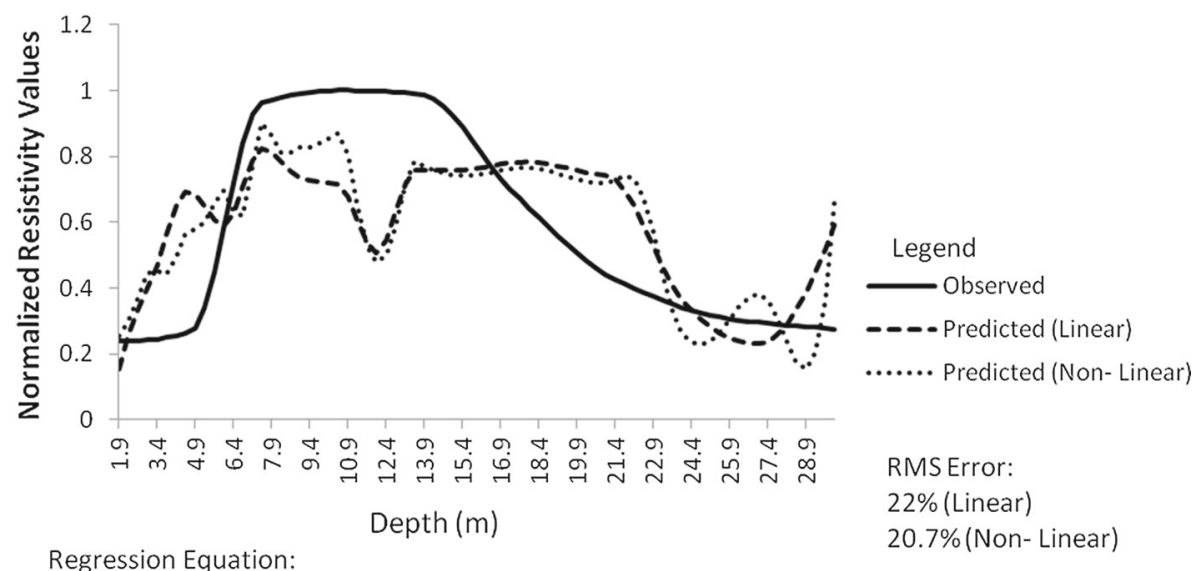

$y=-0.202 x_{1}-0.821 x_{2}+0.906 x_{3}+0.199($ Linear $)$

$y=0.193 x_{1}-5.220 x_{2}-13.493 x_{3}-1.905 x_{1}^{2}+2.906 x_{2}^{2}+8.475 x_{3}{ }^{2}+7.859$ (Non- Linear)

(c)

Figure 6. Observed and predicted (both linear and non-linear) SPT 'N', chargeability and resistivity curves at B33, profile A-B. (a) SPT 'N' curves. (b) Chargeability curves. (c) Resistivity curves. 


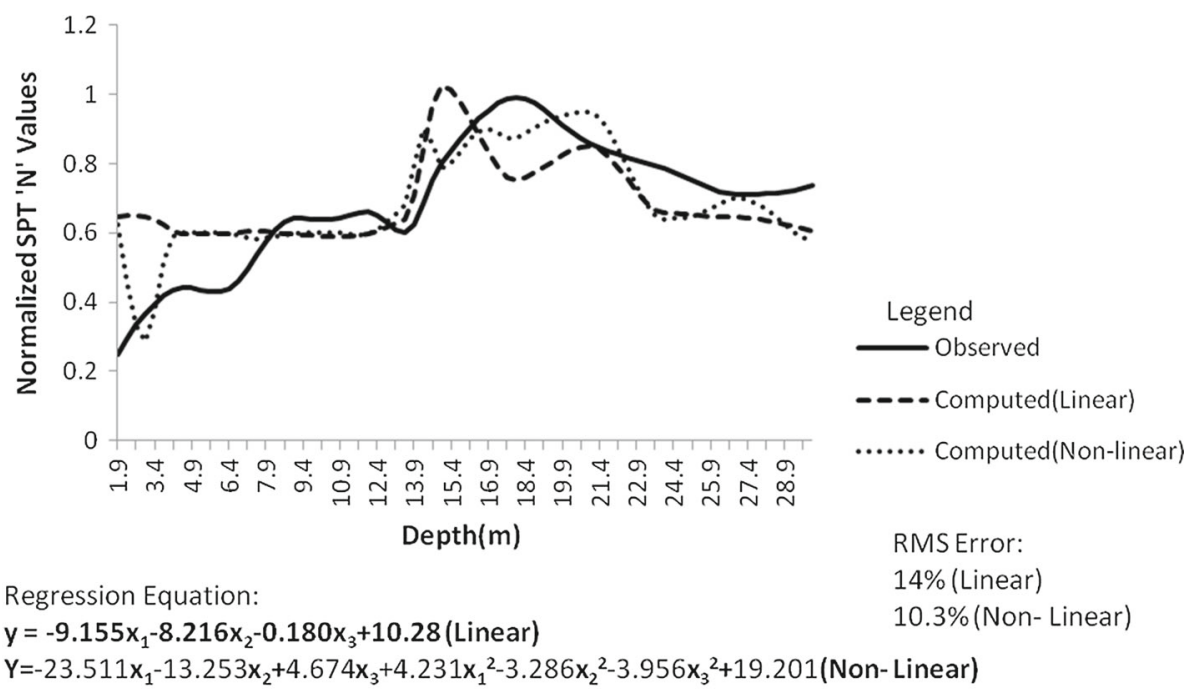

(a)
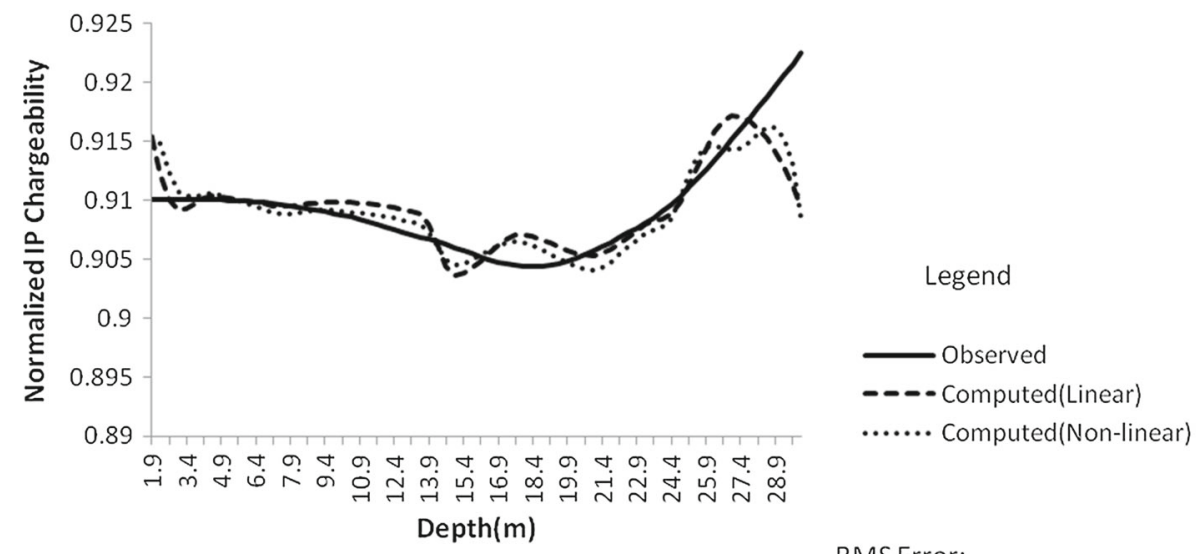

RMSError:

$0.26 \%$ (Linear)

Regression Equation:
$y=0.149 x_{1}+0.145 x_{2}+0.0054 x_{3}+0.750$ (Linear)

$0.24 \%$ (Non- Linear) $y=1.584 x_{1}+.092 x_{2}-.012 x_{3}-.724 x_{1}{ }^{2}+.565 x_{2}{ }^{2}+.016 x_{3}{ }^{2}+.044$ (Non- Linear)

(b)

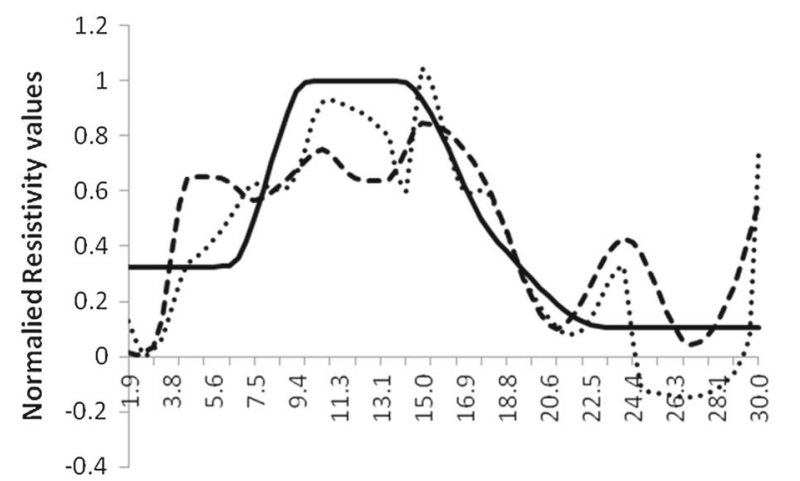

Regression Equation:

$\mathrm{y}=8.260 \mathrm{x}_{1}+7.555 \mathrm{x}_{2}+1.330 \mathrm{x}_{3}-8.753$ (Linear)

$y=3.645 E-12 \operatorname{EXP}\left(26.64 x_{1}\right)-2.006 \operatorname{EXP}\left(-20.981 x_{2}\right)+0.094 \operatorname{EXP}\left(2.854 x_{3}\right)-0.24$ (Non- Linear)

(c)

Figure 7. Observed and predicted (both linear and non-linear) SPT 'N', chargeability and resistivity curves at B35, profile C-D. (a) SPT 'N' curves. (b) Chargeability curves. (c) Resistivity curves. 


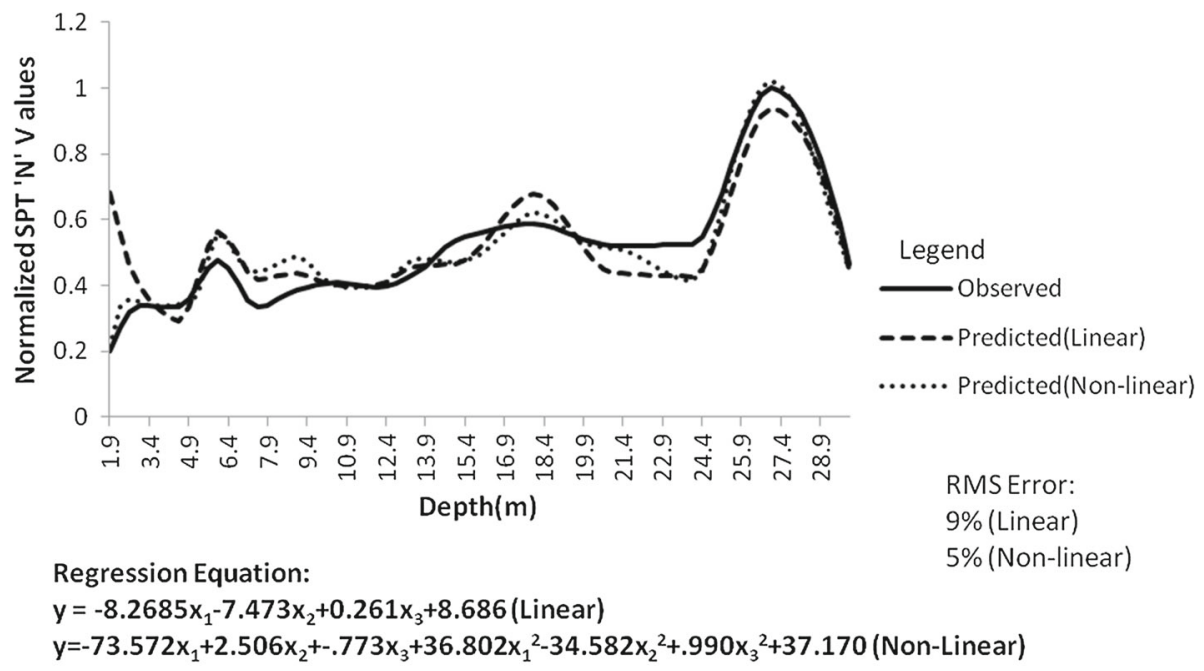

(a)

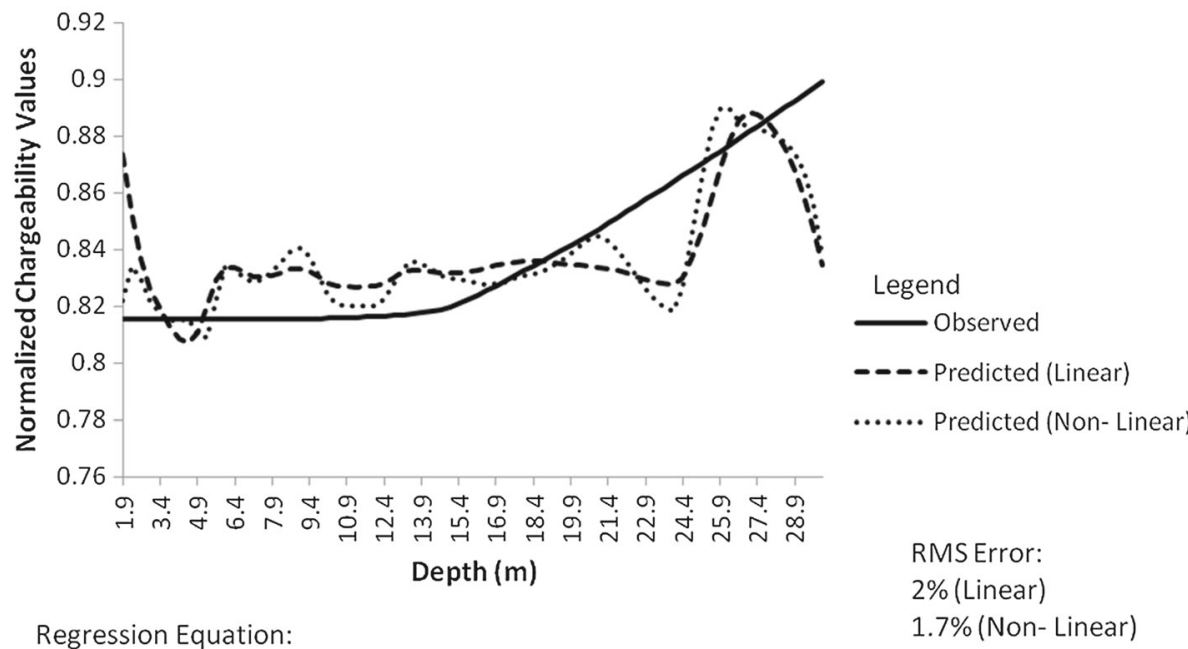

$y=-0.059 x_{1}+0.006 x_{2}+0.048 x_{3}+0.85$ (Linear)

$y=-9.122 x_{1}+1.454 x_{2}-.201 x_{3}+5.085 x_{1}^{2}-4.893 x_{2}^{2}+.238 x_{3}^{2}+4.840$ (Non- Linear)

(b)

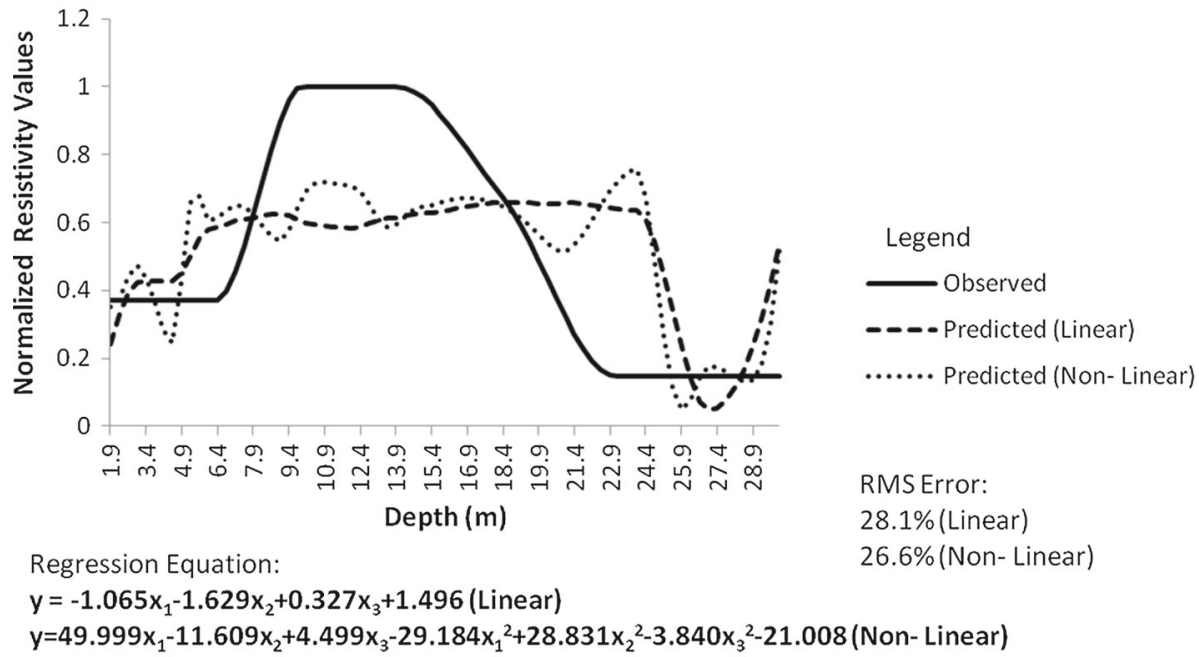

(c)

Figure 8. Observed and predicted (both linear and non-linear) SPT 'N', chargeability and resistivity curves at B36, profile C-D. (a) SPT 'N' curves. (b) Chargeability curves. (c) Resistivity curves. 
There could be many other options. However, one should choose a set of parameters that influence both sets of data. We elaborate this argument. Water salinity could be an important parameter, which could influence resistivity data but not SPT or IP measurements. Likewise, choice of soil consolidation parameter influences resistivity and SPT but not IP measurements. Similar arguments can

Table 3. Multiple linear regression analysis output for SPT ' $N$ ' of borehole B13, profile A-B (figure 1).

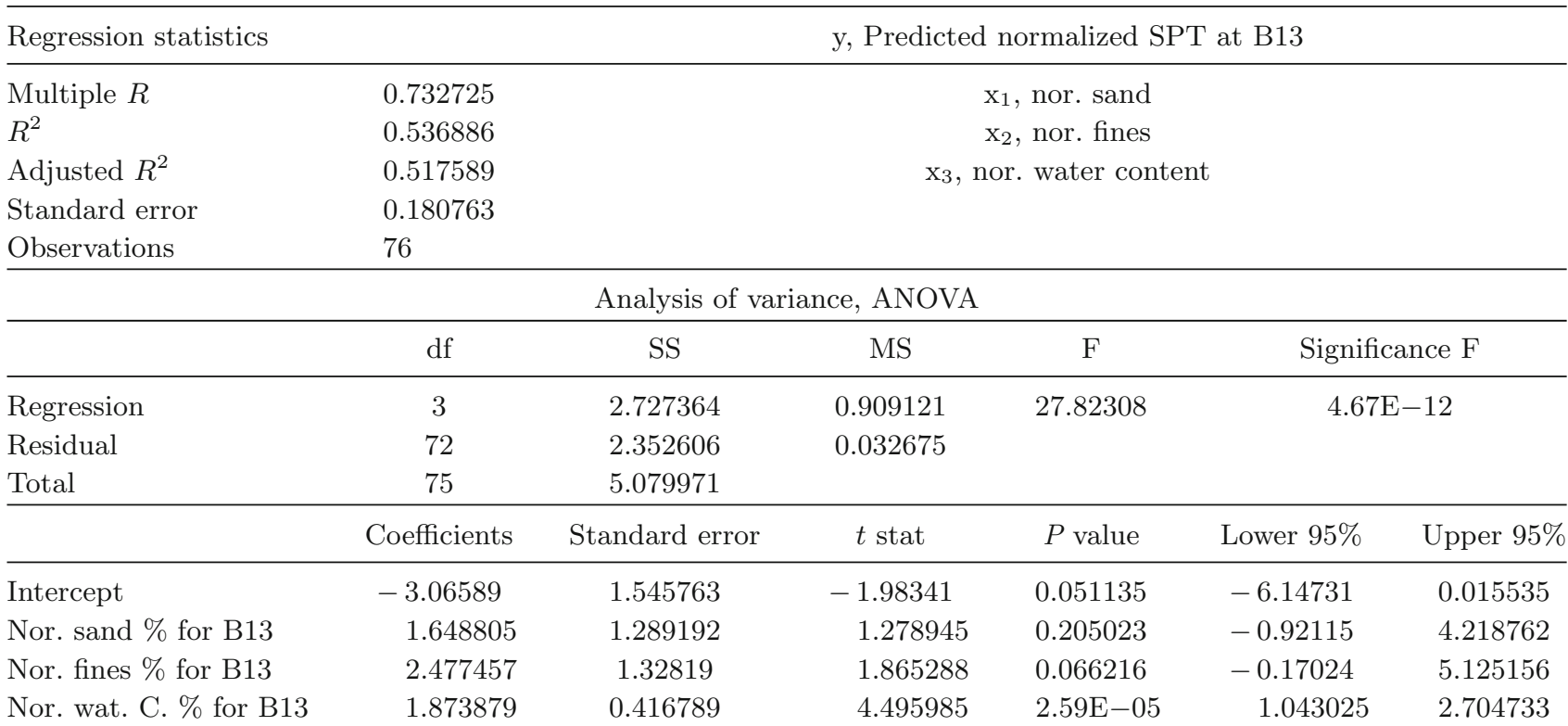

Linear regression equation for normalized SPT at borehole B13

Regression equation: $\mathrm{y}=1.649 \mathrm{x}_{1}+2.477 \mathrm{x}_{2}+1.874 \mathrm{x}_{3}-3.06589$

$54 \%$ of the change in normalized SPT ' $\mathrm{N}$ ' value at borehole B13 can be explained by the changes in the three independent variables, viz., normalized values of sand (\%), fines (\%), water content (\%) (as per our developed code).

Table 4. Multiple linear regression analysis output for chargeability of borehole B13, Profile A-B (figure 1).

\begin{tabular}{|c|c|c|c|c|c|c|}
\hline Regression statistics & & \multicolumn{5}{|c|}{ y, Predicted normalized chargeability at B13 } \\
\hline Multiple $R$ & 0.72343 & \multicolumn{5}{|c|}{$\mathrm{x}_{1}$, nor. sand } \\
\hline$R^{2}$ & 0.52335 & \multicolumn{5}{|c|}{$\mathrm{x}_{2}$, nor. fines } \\
\hline Adjusted $R^{2}$ & 0.50349 & \multicolumn{5}{|c|}{$\mathrm{x}_{3}$, nor. water content } \\
\hline Standard error & 0.059983 & & & & & \\
\hline Observations & 76 & & & & & \\
\hline \multicolumn{7}{|c|}{ Analysis of variance, ANOVA } \\
\hline & df & SS & MS & $\mathrm{F}$ & \multicolumn{2}{|c|}{ Significance F } \\
\hline Regression & 3 & 0.284437 & 0.094812 & 26.35145 & \multicolumn{2}{|c|}{$1.3 \mathrm{E}-11$} \\
\hline Residual & 72 & 0.259056 & 0.003598 & & & \\
\hline \multirow[t]{2}{*}{ Total } & 75 & 0.543493 & & & & \\
\hline & Coefficients & Standard error & $t$ stat & $P$ value & Lower $95 \%$ & Upper $95 \%$ \\
\hline Intercept & -1.87493 & 0.512938 & -3.65528 & 0.000485 & -2.89745 & -0.85241 \\
\hline Nor. sand $\%$ for B13 & 1.898848 & 0.427799 & 4.438649 & $3.2 \mathrm{E}-05$ & 1.046047 & 2.751649 \\
\hline Nor. fines $\%$ for B13 & 2.14073 & 0.44074 & 4.85713 & $6.73 \mathrm{E}-06$ & 1.262132 & 3.019329 \\
\hline Nor. wat. C. $\%$ for B13 & 0.51229 & 0.138305 & 3.704051 & 0.000413 & 0.236583 & 0.787996 \\
\hline
\end{tabular}

Linear regression equation for normalized IPI at borehole B13

Regression equation: $\mathrm{y}=1.899 \mathrm{x}_{1}+2.141 \mathrm{x}_{2}+0.512 \mathrm{x}_{3}-1.87493$

$52 \%$ of the change in normalized chargeability at borehole B13 can be explained by the changes in the three independent variables, viz., normalized values of sand (\%), fines (\%), water content (\%) (as per our developed code). 

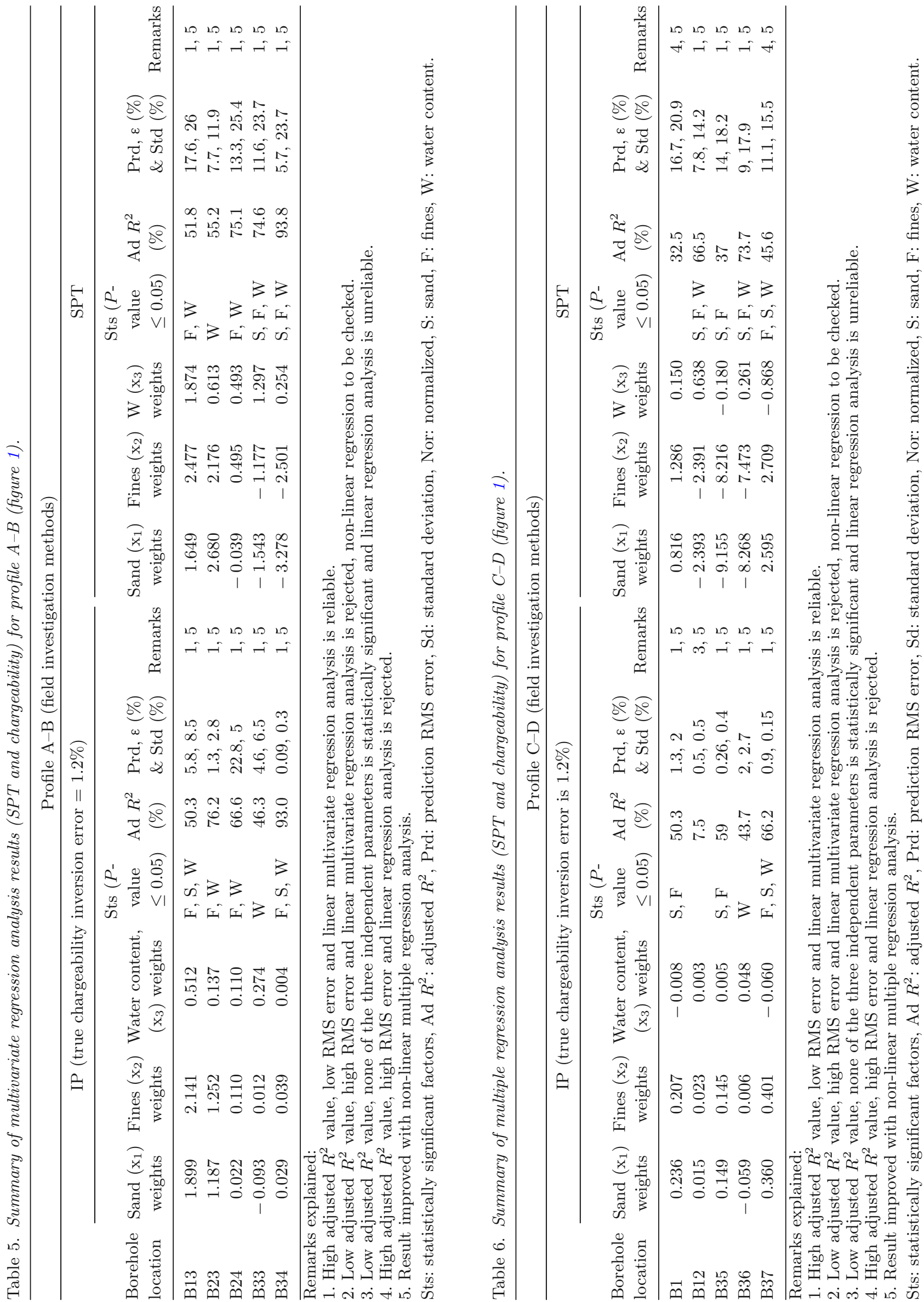


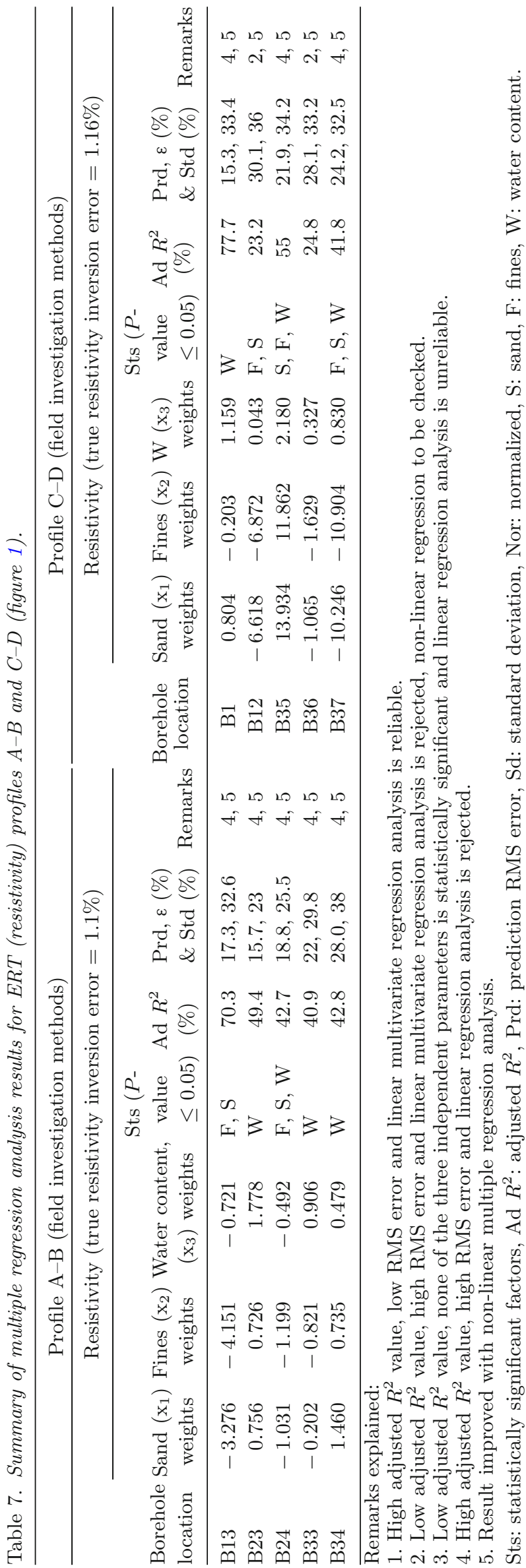

be extended to other index properties of soils and influencing parameters. In all such cases, one should have access to quantifiable independent parameters at large number of boreholes, which can be correlated with geoelectric logs at their respective positions on relevant profiles (ref. figure 1).

The multiple regression analysis shows that the factors influencing the measurements are sitespecific and subsurface lithology dependent. As an example, multiple regression results for SPT and IPI for borehole location B13 (profile A-B, figure 1) are shown in tables 3 and 4 . Similar analysis was made for all boreholes on both profiles, A$\mathrm{B}$ and $\mathrm{C}-\mathrm{D}$ (figure 1). Accrued linear multiple regression results are included in tables 5 and 6 and that of ERT separately in table 7 . We tried nonlinear multiple regression and the results got improved. A comparative linear versus nonlinear multiple regression results are included in table 8 .

In linear multiple regression cases of bad performance, implementation of nonlinear regression (tables 5-7) has led to a better prediction of dependent parameters (SPT, chargeability and resistivity). High prediction error for SPT (figures 5a, $6 \mathrm{a}, 7 \mathrm{a}$ and $8 \mathrm{a}$ ) can be attributed to the data scatter shown for profiles $\mathrm{A}-\mathrm{B}$ and $\mathrm{C}-\mathrm{D}$ in figure $4(\mathrm{a}-\mathrm{d})$. In the same vein, the better performance of IPI (figures 5b, 6b, 7b and 8b) can also be similarly explained. However, ERT fared badly in the study region mainly due to predominance of subsurface clay and non-inclusion of salinity factor as an independent variable. Further, resistivity is related to chosen independent parameters broadly in a nonlinear fashion. A quantitative salinity estimate of soil water content in independent set of parameters in multiple regression study could have led to a better prediction of resistivity. However, the earlier arguments go in favour of its non-inclusion.

In the present study, ad $R^{2} \leq 30 \%$ is treated as low (tables 5-7) for predicted SPT-N, ERT (resistivity) and IPI (chargeability). Accordingly, tables 5-7 carry abbreviated remarks, which were explained in the respective footnotes.

\section{Conclusions}

In order to use geoelectric imaging in geotechnical site investigations, a multiple regression analysis of both geoelectric imaging and geotechnical site investigation results is a must. Results achieved in the present studyindicate that sand, fines and 
Table 8. RMS error details in predicting SPT ' $N$ ', chargeability and resistivity through multivariate regression analysis (linear and non-linear) for borehole locations falling on profiles $A-B$ and $C-D$ (figure 1).

\begin{tabular}{|c|c|c|c|c|c|c|}
\hline \multirow{3}{*}{$\begin{array}{l}\text { Borehole } \\
\text { no. }\end{array}$} & \multicolumn{6}{|c|}{ RMS error (\%) } \\
\hline & \multicolumn{2}{|c|}{ SPT 'N' } & \multicolumn{2}{|c|}{ Chargeability } & \multicolumn{2}{|c|}{ Resistivity } \\
\hline & Linear & Nonlinear & Linear & Nonlinear & Linear & Nonlinear \\
\hline B1 & 16.7 & 11.3 & 1.3 & 1 & 15.3 & 13.2 \\
\hline B12 & 7.8 & 6.2 & 0.5 & 0.4 & 30.1 & 26.7 \\
\hline B13 & 17.6 & 7 & 5.8 & 4 & 17.3 & 14.6 \\
\hline B23 & 7.7 & 6.5 & 1.3 & 0.5 & 15.7 & 13.2 \\
\hline B24 & 12.3 & 10.4 & 2.8 & 2.5 & 18.8 & 16 \\
\hline B33 & 11.6 & 10.7 & 4.6 & 4 & 22 & 20.7 \\
\hline B34 & 5.7 & 4.5 & 0.09 & 0.05 & 28 & 26.7 \\
\hline B35 & 14 & 10.3 & 0.26 & 0.24 & 21.9 & 18.5 \\
\hline B36 & 9 & 5 & 2 & 1.7 & 28.1 & 26.6 \\
\hline B37 & 11.1 & 9.2 & 0.9 & 0.8 & 24.2 & 24 \\
\hline Average error & 11.35 & 8.11 & 1.96 & 1.52 & 22.14 & 20.02 \\
\hline $\begin{array}{l}\text { Decrease in error }(\%) \\
\text { from linear to nonlinear }\end{array}$ & \multicolumn{2}{|c|}{28.55} & \multicolumn{2}{|r|}{22.45} & \multicolumn{2}{|r|}{9.58} \\
\hline
\end{tabular}

water content influence both geoelectric imaging (ERT/IPI) and geotechnical site investigation test (SPT) results. The contribution of different formation parameters is similar in majority of cases for geoelectrical (IP) and geotechnical (SPT) parameters. Also, SPT test results are predicted with high error in comparison to IP test results. It may indicate inclusion of additional independent parameters (plasticity index, pore pressure coefficient, over-consolidation ratio) for improving the regression performance of SPT. But any such choice is constrained by their influence on other dependent variables. Our results indicate that both geoelectric and geotechnical test results are affected predominantly non-linearly by sand, fines and water content of subsurface and the extent of their exact influence is guided by local nearsurface lithological variations. Thus, this study will provide a basic logic in the conjunctive use of non-invasive and cost-effective geoelectric imaging and minimum invasive geotechnical test results in geotechnical characterization of a project site.

\section{Acknowledgements}

Authors thank the unknown reviewer for the excellent review. Ms. Sumedha conveys her sincere thanks to Ministry of Human Resources Development (MHRD), Government of India for the research fellowship.

\section{References}

Börner F D, Schopper J R and Weller A 1996 Evaluation of transport and storage properties in the soil and groundwater zone from induced polarization measurements; Geophys. Prospect. 44 583-601.

Bowles J S 2001 Foundation Analysis and Design; 5th edn, Mc-Graw Hill International, Singapore, 171p.

Craig R F 1978 Soil Mechanics; 2nd edn, Van Nostrand Reinhold Co., London, 458p.

Gautam P K, Sastry R G and Mondal S K 2007 The utility of multi-electrode resistivity data in geotechnical investigations - A case study; 20th Symposium on the Application of Geophysics to Engineering and Environmental Problems (SAGEEP), pp. 731-737.

Gupta S, Sundaram R and Gupta S 2010 Dynamic compaction to mitigate liquefaction potential; Indian Geotechnical Conference, Mumbai Chapter, IIT Bombay.

Kiberu J 2002 Induced polarization and resistivity measurements on a suite of near surface soil samples and their empirical relationship to selected measured engineering parameters; Thesis of Master of Science in Applied Geophysics, International Institute for Geo-Information Science and Earth Observation, Enschede, The Netherlands, 119p.

Kikon N and Singh P 2014 Temporal analysis of land use pattern changes of Noida, NCR Using Geospatial Tools; 15th ESRI India User Conference, 3.

Kleinbaum D G, Kupper L L, Nizam A and Rosenberg E S 1988 Applied regression analysis and other multivariable methods; PWS Publishing Co., Boston, MA, USA, 718p.

Knight R, Pyrak-Nolte L J, Slater L, Atekwana E, Endres A, Geller J, Lesmes D, Nakagawa S, Revil A, Sharma M M and Straley C 2010 Geophysics at the interface: Response of geophysical properties to solid-fluid, fluid-fluid, and solid-solid interfaces; Rev. Geophys. 48 1-30. 
Krishnan M S 1986 Geology of India ES Burma; CBS Publishers, New Delhi.

Lesmes D P and F D Morgan 2001 Dielectric spectroscopy of sedimentary rocks; J. Geophys. Res. 106329 346.

Li Y and Oldenburg D W 1991 Aspects of charge accumulation in DC resistivity experiments; Geophys. Prospect. 39 803-826.

Loke M H and Barker R D 1995 Least-squares deconvolution of apparent resistivity pseudosections; Geophysics $\mathbf{6 0}$ 1682-1690.

Marshall D J and Madden T R 1959 Induced polarization, a study of its causes; Geophysics 24 790-816.

Murthy V N S 2008 Soil Mechanics and Foundation Engineering; CBS Publisher and Distributors, 1043p.

Niwas S, Gupta P K and de Lima O A L 2006 Nonlinear electrical response of saturated shaley sand reservoir and its asymptotic approximations; Geophysics 71 G129G133.

Niwas S, Gupta P K and de Lima O A L 2007 Nonlinear electrical conductivity response of shaly-sand reservoir; Curr. Sci. 92 612-617.

Patella D 1973 A new parameter for the interpretation of induced polarization field prospecting (time-domain); Geophys. Prospect. 21 315-329.

Parkash B, Kumar S, Rao M S, Giri S C, Kumar C S and Gupta S 2001 Active tectonics of western Gangetic Plains; In: Seismicity, IGC (ed.) Verma O P, DST's Spec. Publ., 2, pp. 141-158.

Pazdirek O and Blaha V 1996 Examples of resistivity imaging using ME-100 resistivity field acquisition system; In: EAGE 58th Conference and Technical Exhibition Extended Abstracts, Amsterdam.

Pidlisecky A, Knight R and Haber E 2006 Cone-based electrical resistivity tomography; Geophysics 71 157-167.

Remai Z 2013 Correlation of undrained shear strength and CPT resistance; Period. Polytech.-Civ. 7 39-44.

Revil A and Glover P W J 1998 Nature of surface electrical conductivity in natural sands, sandstones, and clays; Geophys. Res. Lett. 25 691-694.

Revil A and Leroy P 2004 Constitutive equations for ionic transport in porous shales; J. Geophys. Res. 109(B3) B03208.

Revil A and Glover P W J 1997 Theory of ionic surface electrical conduction in porous media; Phys. Rev. B. 55 1757-1773.

Revil A, Cathles, L M S, Losh S and Nunn J A 1998 Electrical conductivity in shaly sands with geophysical applications; J. Geophys. Res. 103 925-936.
Sastry R G, Gautam P K and Viladkar M N 2012 Geo-electrical imaging based in-situ and site-specific transforms for geotechnical characterization of a civil construction site, SAGEEP, Tucson, Arizona, USA.

Sastry R G, Sumedha and Mondal S K 2013 Role of geoelectrical imaging in geotechnical site investigations when conventional geotechnical tests fail, Symposium on the Application of Geophysics to Engineering and Environmental Problems, SAGEEP, Boston, USA.

Shevnin V, Mousatov A, Ryjov A and Delgado-Rodriquez O 2007 Estimation of clay content in soil based on resistivity modelling and laboratory measurements; Geophys. Prospect. 55 265-275.

Slater L D and Glaser D R 2003 Controls on induced polarization in sandy unconsolidated sediments and application to aquifer characterization; Geophysics 68 15471558 .

Slater L and Lesmes D P 2002 Electrical-hydraulic relationships observed for unconsolidated sediments; Water Resour. Res. 381213.

Sumedha and Sastry R G 2016 Multivariate regression analysis of geoelectric imaging and geotechnical test results, Symposium on the Application of Geophysics to Engineering and Environmental Problems SAGEEP, Denver, USA.

Sumner J S 1976 Principles of Induced Polarization for Geophysical Exploration; Elsevier, Amsterdam, 277p.

Terzaghi K 1943 Theoretical Soil Mechanics; Wiley \& Sons, New York, 510p.

Terzaghi K and Peck R B 1996 Soil Mechanics in Engineering Practice; 3rd edn, John Wiley \& Sons, New York.

Titov K, Komarov V, Tarasov V and Levitski A 2002 Theoretical and experimental study of time-domain induced polarization in water-saturated sands; J. Appl. Geophys. 50 417-433.

Titov K, Kemna A, Tarasov A and Vereecken H 2004 Induced polarization of unsaturated sands determined through time domain measurements; Vadose Zone J. 3 1160-1168.

Vinegar H J and Waxman M H 1984 Induced-polarization of shaly sands; Geophysics 49 1267-1287.

Worthington P F and Collar F A 1984 Relevance of induced polarization to quantitative formation evaluation; Mar. Petrol. Geol. 1 14-26.

Yoon H K, Kim J H, Kim R and Lee J S 2009 Electrical resistivity and cone tip resistance monitoring by using cone resistivity penetrometer, Abstract in Proceedings of the 19th International Offshore and Polar Engineering Conference, Osaka, Japan, 168p. 